\title{
Reasons for presenteeism in nurses working in geriatric settings: A qualitative study
}

\author{
Luke Anthony Fiorini*1,2, Amanda Griffiths ${ }^{1}$, Jonathan Houdmont ${ }^{1}$ \\ ${ }^{1}$ Faculty of Medicine \& Health Sciences, University of Nottingham, Nottingham, United Kingdom \\ ${ }^{2}$ Centre for Labour Studies, University of Malta, Malta
}

Received: March 3, 2018

Accepted: April 27, 2018

Online Published: May 2, 2018

DOI: $10.5430 /$ jha.v7n $4 p 9$

URL: https://doi.org/10.5430/jha.v7n4p9

\begin{abstract}
Objective: To explore the perceived causes of presenteeism in nurses on geriatric wards.

Background: Presenteeism, defined as working when unwell, is associated with lost productivity and increased absenteeism. It is more commonly reported by employees in the healthcare sector than other sectors.

Methods: An exploratory, qualitative study using semi-structured interviews, thematically analysed. Data collected via 18 recorded interviews with nurses working with patients on geriatric medical wards in Malta.

Results: Four major themes emerged that related to nurses' decisions to engage in presenteeism: illness perceptions, which included participants' views and experiences of their own health complaints; attitudes to their employing organisation, co-workers and patients; organisational aspects such as culture and administrative arrangements; and personal reasons including illness behaviour preference and personal circumstances.

Conclusions: Nurses' decisions to attend work when unwell were reported as dependent upon four themes. Further studies are warranted to determine if findings are applicable to nurse populations other than those represented in this study.

Implications: Workplace health promotion initiatives should target nurses' management of their own health, particularly if they have chronic illnesses. Workplace policies and arrangements should be examined with a view to controlling presenteeism.
\end{abstract}

Key Words: Presenteeism, Delivery of health care, Nursing health, Qualitative research

\section{INTRODUCTION}

Interest in presenteeism, conceptualised most frequently as attending work whilst unwell, ${ }^{[1]}$ stems in part from evidence that associated productivity losses may be considerable. Some have estimated such losses to exceed those associated with absenteeism. ${ }^{[2]}$ It has been argued that presenteeism can deprive ill workers of necessary recuperation opportunities, ${ }^{[3]}$ resulting in future absenteeism. ${ }^{[4]}$ In healthcare contexts, research has associated presenteeism in nurses with increased patient falls, medication errors and lower quality-of-care scores. $^{[5]}$
A number of studies in the wider literature have examined the antecedents of presenteeism. These have included healthrelated factors such as poor levels of health, ${ }^{[6]}$ minor illnesses, ${ }^{[7]}$ and illnesses with a low risk of contagion. ${ }^{[8]}$ Attitudes to work and organisational factors have also been implicated. A meta-analysis ${ }^{[6]}$ concluded that positive job attitudes motivated individuals to engage in presenteeism. The study also noted that job demands such a high workload, overtime, time pressures, lack of staff and the physical demands of the job may all drive presenteeism. Findings on the role of peer and supervisor support have been mixed, with

*Correspondence: Luke Anthony Fiorini; Email: luke.fiorini@um.edu.mt; Address: Centre for Labour Studies, University of Malta, Malta. 
some quantitative studies indicating a negative association with presenteeism ${ }^{[9,10]}$ and others failing to identify a relationship. ${ }^{[11]}$ Mixed findings have also been demonstrated in relationship to teamwork ${ }^{[12,13]}$ and job insecurity. ${ }^{[14,15]}$ Much of this research has used quantitative research methods and, with a few exceptions ${ }^{[6]}$ has been a-theoretical. ${ }^{[16]}$

Interest in the predictors of presenteeism in healthcare workers emerged following findings that presenteeism rates tend to be higher in the healthcare sector in comparison with other sectors. ${ }^{[17]}$ The available literature, emerging from several countries, is limited and reports an inconclusive picture. For example, qualitative findings illustrated that various factors, including perceptions of what constitutes an acceptable cause of absence, influenced Norwegian and Danish nursing home staff decisions to attend or not attend work when unwell. ${ }^{[18]}$ In one mixed methods study of American healthcare workers, concerns over staffing levels and the adverse repercussions of non-attendance for co-workers and patients influenced decisions to engage in presenteeism. ${ }^{[19]}$ In a quantitative study, perceived pressure from co-workers and supervisors drove presenteeism. ${ }^{[7]}$ And finally, in Swiss healthcare workers, quantitative findings demonstrated that low staffing levels were linked to higher levels of presenteeism and supportive leadership was related to a lower likelihood of such behaviour. ${ }^{[13]}$ There have been few qualitative explorations of presenteeism in healthcare settings. These would allow an in-depth investigation into individuals' experience of presenteeism, and their explanations about why they choose to attend, rather than not to attend, work when unwell. In view of the mixed findings in this respect, more qualitative research is warranted.

The European Working Conditions Survey ${ }^{[20]}$ reported absenteeism and presenteeism in Malta to be amongst the highest in the European Union. But otherwise presenteeism has not been the topic of published study in this country. Following discussions by the first author with nursing management of two public hospitals in Malta, both specialising in the care of older adults, it transpired that both absenteeism and presenteeism were thought to be commonplace. It was additionally reported that managing presenteeism was difficult since true rates and aetiological factors were unknown. A study was therefore undertaken to explore the perceived causes of both these illness behaviours. This paper presents the results and conclusions related to the perceived reasons for presenteeism.

\section{Methods}

\subsection{Research setting}

The current investigation was undertaken at two state-owned, medical facilities in Malta, both of which catered for the needs of older patients. Together, the two facilities provided
1,340 in-patient beds serviced by 410 nurses. Of these, 74 were charge nurses or deputy charge nurses. These latter groups had additional management duties, each being responsible for, or assisting, respectively in the running of a ward. Nurses who did not work on a ward, for example in an outpatient department, were excluded.

\subsection{Research design}

An exploratory study that made use of a qualitative research methodology was conducted to identify the factors believed to influence presenteeism in nurses working within geriatric ward settings. The study design was chosen due to the lack of previous studies on presenteeism in Malta, as well as due to the lack of comprehensive presenteeism theory.

\subsection{Procedure}

Stratified random sampling was employed to identity potential nurses from the two participating medical facilities. The Heads of Nursing produced lists of nurses and charge nurses, each allocated a number, and the first author drew numbers from a hat. He was then provided with the corresponding nurses' contact details and approached them during work hours to explain the purpose of the study and what participation would entail. The voluntary nature of the study, the right to withdraw, and the protection of identity in outcomes, was explained. One potential participant declined to be interviewed. Written information was provided and consent obtained.

Semi-structured interviews took place in a private room within the participants' wards. These were audio recorded, and lasted between 40 and 70 minutes. All interviews were conducted by the first author (LF). When the interviewer considered that saturation had been reached, no more interviews took place. Eighteen full-time nurses, 14 females and 4 males, were interviewed. Their ages ranged from 22-62. Eight were charge/deputy charge nurses. All worked 12-hour shifts.

Open-ended interview questions were informed by the literature and consultative meetings with the respective heads of nursing in the participating organisations. Participants were asked to describe occasions when they had engaged in presenteeism and to reflect on reasons for their choice. Coworkers' illness behaviour and whether or not it impacted upon participants' behaviour, was also explored. Finally, participants were asked if other factors relevant to presenteeism existed that had not been thus far explored in the interview.

The study was approved by the Research Ethics Committee of the Faculty of Medicine and Health Sciences, University of Nottingham. Written permission was granted by the two participating organisations to carry out the study. 


\subsection{Analysis}

A thematic analysis was undertaken by the first author (LF) using Braun and Clarke's six-stage framework: ${ }^{[21]}$ (1) Interview recordings were transcribed and transcripts re-read to ensure familiarisation with the data, (2) Codes, representing a category of information relating to the study's broad aims, were developed, (3) Coded data were collated and a search for candidate themes, by means of an inductive approach, was conducted, (4) The devised themes were reviewed to ensure a coherent pattern within each theme, to ascertain that an accurate thematic map of the entire dataset had been obtained, and were discussed between all three authors, (5) Themes and sub-themes were named and defined, and (6) A report was prepared which included extracts from the transcripts to illustrate each of the themes. Data collection and analysis were completed midway through 2015.

A number of procedures were used to establish the validity and credibility of the findings. During data collection, the interviewer verbally fed back the information received from interviewees as a means of accuracy checking. Transcripts and emergent themes were discussed by all authors. Finally, the first author held meetings with members of the hospitals' administration, during which the emergent themes were presented and their opinion elicited. It was concluded that the findings were reflective of the situation on the wards.

\section{RESULTS}

Four overarching themes were identified: illness perceptions, attitudes, organisational aspects, and personal reasons. These top-level themes, their sub-themes, and frequencies are presented in Table 1. There were some differences in the importance of some sub-themes for nurses with management roles (charge nurses) and those without. Themes and illustrative quotations are presented below.

Table 1. Thematic analysis coding template

\begin{tabular}{|c|c|c|c|}
\hline Theme & Sub-themes & Theme description & $\begin{array}{l}\text { Number of respondents } \\
\text { mentioning this theme } \\
\text { one or more times }(\%)\end{array}$ \\
\hline \multirow{6}{*}{$\begin{array}{l}\text { Illness } \\
\text { perceptions }\end{array}$} & - Identity & - Description of the illness and/or associated symptoms. & $16(89)$ \\
\hline & - Timeline & - Temporal aspects of an illness. & $18(100)$ \\
\hline & - Cure and control & - Perception of control and/or recovery from an illness. & $18(100)$ \\
\hline & - Cause & - Factors thought to have contributed to the illness. & $9(50)$ \\
\hline & - Consequence & - The effects and outcomes of the illness. & $16(89)$ \\
\hline & - Coherence & - Understanding of one's illness. & $8(44)$ \\
\hline \multirow{3}{*}{ Attitudes } & $\begin{array}{l}\text { Work and the } \\
\text { organisation }\end{array}$ & - Approach and concern towards work tasks and the organisation. & $17(94)$ \\
\hline & - Co-workers & - Concern regarding co-workers. & $15(83)$ \\
\hline & - Patients & - Concern towards patients. & $3(17)$ \\
\hline \multirow{2}{*}{$\begin{array}{l}\text { Organisational } \\
\text { aspects }\end{array}$} & - Work environment & - The immediate organisational and psychosocial work environment. & $14(78)$ \\
\hline & $\begin{array}{l}\text { - Administrative } \\
\text { measures }\end{array}$ & - Wider administrative rules which influenced nurses' behaviour. & $11(61)$ \\
\hline \multirow{2}{*}{$\begin{array}{l}\text { Personal } \\
\text { reasons }\end{array}$} & $\begin{array}{l}\text { - Illness behaviour } \\
\text { preferences }\end{array}$ & $\begin{array}{l}\text { - Proclivity for presenteeism and perception of illness behaviour } \\
\text { legitimacy. }\end{array}$ & $16(89)$ \\
\hline & - Personal life & - Influence of situation at home. & $8(44)$ \\
\hline
\end{tabular}

\subsection{Illness perceptions}

This theme, which dealt with participants' perceptions of their own health and illnesses, included six sub-themes.

(1) Identity: Certain symptoms, such as musculoskeletal pain or sneezing, were commonly linked with presenteeism, whilst others such as gastric symptoms and surgery were not. Illnesses considered to be minor were more likely to lead to presenteeism than those considered to be serious.

"If it's not severe, I just don't make any decision, I just come here and that's it. I don't stay home."
(2) Timeline: Chronic illnesses and those that required a long time to recover appeared to necessitate presenteeism. A number of individuals noted that this was driven by restrictions in permissible sick leave days.

"I come [to work] because it is not something that happens once in a while, it is something I'm living with."

(3) Cure and control: Conditions considered controllable were associated with presenteeism. Controllability was most frequently achieved by means of medication, however behaviour changes, such as taking a bathroom break to reduce 
stress, or modifying tasks to prevent pain were also employed.

Another consideration was the perceived consequence of presenteeism for the illness. Individuals attended ill when they felt that: (a) Attending would help (or distract them from) their symptoms; (b) Their illness would improve despite presenteeism; and (c) Absenteeism was not associated with recovery, often because the condition was chronic or because staying home would not result in rest due to domestic tasks.

"So when I'm here moving around, walking, giving out stuff, I ignore it. I don't pay attention to it. . If I stay home I feel it more, I concentrate more on it, and I feel it more."

(4) Cause: Participants expressed acceptance or helplessness that nursing was frequently hazardous and that certain diseases, such as back pain, were common. Nursing was believed to exacerbate chronic conditions and necessitated presenteeism.

"Back pain - I think the majority of nurses suffer from it. You learn to live with it! I think it is part of the job, I think it's very common."

(5) Consequence: Individuals explained that they engaged in presenteeism when an illness was not contagious and/or that they could cope with work demands. Coping depended on many other issues such as workload, teamwork and how well symptoms could be managed.

"Wearing a support and stuff, I can manage. I am carrying the same weight, lifting, I am working to my capability."

(6) Coherence: Participants reported that when they were familiar with an illness they could more easily determine whether they could engage in presenteeism or not. This was often linked to the aforementioned sub-themes, for example perceived controllability and consequences, and emerged from past experience, medical training and advice from medical professionals.

"We are nurses, so we know exactly the process of a disease... I think it's a plus."

\subsection{Attitudes}

Participants' attitudes to their employer, co-workers and patients played a role in determining if they attended work when unwell.

(1) Attitude towards work and the organisation: Participants discussed how they enjoyed, and were satisfied or proud of various aspects of their work and that this facilitated presenteeism. They reported engaging in presenteeism due to strong feelings of responsibility, with charge nurses stating that they felt ownership of their ward, experienced feelings of indispensability and an awareness that work piled up when they did not attend.

"So I think that if you are happy at the place of work, it is stressful, it is hectic, but I'm happy. I think that prevents you from taking sick leave."

(2) Attitudes towards co-workers: Participants described how they engaged in presenteeism to avoid burdening co-workers with additional work:

"I know that when we are short of staff, my friends and I suffer more. We end up with an overload of work. And obviously here, we are in a hospital, and you never know what can happen."

Additionally, it was noted that replacements were often relief staff who, being unfamiliar with ward procedures and patients, could further burden co-workers. Charge nurses reported attending work when unwell as they were not usually replaced by someone at a similar level of seniority and thus felt their absence would burden the most senior nurse otherwise present on the ward.

Nurses also reported attending because they feared coworkers' vacation leave could be cancelled due to staff shortages. Additionally, participants who had recently been on sick leave reported engaging in presenteeism.

"Before, I had also taken some sick leave. It was earlier, maybe three weeks before, and I felt guilty about taking sick leave again."

(3) Attitude towards patients: A few participants also admitted that their familiarity with patients (many of whom, in geriatric wards, were long-stay patients) encouraged presenteeism. This occurred because participants either admitted to considering patients as friends, or stated that patients had grown attached to the staff and were not keen to be seen by unfamiliar relief staff.

“... the patients are attached to the staff. This patient I'm thinking of always wants us. And if relief staff go and clean him up, he wouldn't want it. He would be angry and he will give them a very hard time... this encourages me to attend because I don't want to leave problems, if it is possible."

\subsection{Organisational aspects}

Participants also described being affected by organisational, systems-level factors when deciding if they should engage in presenteeism.

(1) Work culture: Good interpersonal relationships between co-workers were reported as encouraging presenteeism:

"If I'm going to be working in the shift I get along with, there 
is more chance of me coming to work."

In some wards, a presenteeism culture was evident; participants described how they felt a social pressure to attend because their co-workers did so too. Good teamwork also played an important role in facilitating presenteeism, helping them to cope with job demands.

Whilst some individuals viewed high workloads as a reason not to attend work when ill, others stated that they did their utmost to attend under such conditions, to support their colleagues.

(2) Administrative arrangements: Participants admitted to engaging in presenteeism when their illness coincided with days that attracted higher levels of pay.

"If it is a Sunday or a public holiday, it is better to come, because Sunday is double the pay and on a public holiday it is triple the pay. So that is a very reasonable reason to come, even if you are sick."

Another administrative aspect that encouraged presenteeism was the policy that vacation leave could not be taken directly after a sick leave day. Participants reported that they had attended when unwell the day prior to pre-booked vacation leave, in order to avoid this being cancelled. And finally, charge nurses reported that as they were permitted to use their vacation leave flexibly, they would often shorten their 12 hour working day when unwell by taking a few hours of vacation leave. This allowed them to attend while unwell to carry out their most important tasks. Less senior nurses however did this less frequently as unlike charge nurses, a replacement needed to be sought in order for them to take a few hours of vacation leave.

\subsection{Personal reasons}

Personal reasons also played a role in instigating presenteeism.

(1) Illness behaviour preferences: Whilst some individuals appeared to favour doing what they could to attend work when unwell, and often took pride in reporting very few instances of sickness absence, others did not. Participants also noted such traits in their co-workers.

Beliefs about the perceived legitimacy of absence behaviour also influenced participants' behaviour. Participants described that they engaged in presenteeism if they felt sickness absence would tarnish their image: for example, when such absence coincided with periods of added responsibility or important meetings. Participants with conditions they believed to be poorly understood (often psychological), reported ambivalent feeling as to whether absence was warranted; some felt presenteeism was necessary as absence would not be

Published by Sciedu Press perceived as legitimate, whilst others favoured absence as they would receive little support when feeling unwell in the workplace.

"If I said 'I am depressed', how could I say that? 'I'm a bit worried, I'm not coming because I am mentally stressed.' Nobody would say that. I don't think people take sick leave for them, they come to work."

(2) Personal life: Some participants explained how aspects of their personal life impacted on their decisions as to attend work when unwell; for example, despite chronic illness they were financially driven to remain employable, they were encouraged to do so by family members, or because they viewed such behaviour as setting a positive example for their children.

"I have two children. You have to go to work... You cannot stay at home and give a bad example that you are always at home."

\section{DiscuSSION}

This study explored the causes of presenteeism in ward-based nurses working with older adults in Malta with a view to the findings informing discussions about the prediction and management of presenteeism. Faced with the decision of attending for work ill, these nurses highlighted four major themes. Illnesses perceived as less severe, longer lasting and manageable were associated with presenteeism, as were positive attitudes towards one's job and co-workers. Appraising work positively as well as policies on remuneration and vocation leave fostered presenteeism. Finally, personal reasons such as illness behaviour preferences also played a role.

\subsection{Illness perceptions}

Participants' perceptions of their illnesses were a major influence in deciding whether to engage in presenteeism. The subthemes discussed within this theme mirrored the aspects first highlighted in the "Common Sense Model (CSM) of SelfRegulation", ${ }^{22,23]}$ whereby individuals as active problemsolvers develop cognitive representations of their illness, which in turn determine how they respond to it. ${ }^{[24]}$ The CSM however has not thus far featured in the presenteeism literature. This suggests a potentially useful opportunity to integrate these perspectives.

The study provides support for previous findings that less severe illnesses, ${ }^{[12]}$ chronic illnesses, ${ }^{[25]}$ and situations thought to benefit, or that would not aggravate, illness ${ }^{[26]}$ encouraged presenteeism. The study also supported previous findings that specific illnesses fostered presenteeism, ${ }^{[10]}$ and that individuals attended ill when they felt they could cope with their work tasks. $^{[27]}$ 


\subsection{Attitudes}

Enjoying one's job and feelings of pride, satisfaction and a sense of responsibility were given as reasons to attend when ill. Similar findings have been previously demonstrated ${ }^{[28,29]}$ and their combination may suggest that work engagement, ${ }^{[30]}$ which has received limited attention in the presenteeism literature, may be relevant and warrant further investigation.

Attending due to difficulties in finding replacements ${ }^{[12]}$ and to avoid burdening co-workers ${ }^{[31]}$ is a common, but not universal finding. ${ }^{[32]}$ Participants appear to have engaged in presenteeism out of choice, rather than due to restrictive policies, and this was further exemplified by other sub-themes such as attending because of familiarity with patients: a consideration previously noted in nurses. ${ }^{[18]}$

\subsection{Organisational aspects}

As in the current study, previous studies have also noted that positive interpersonal and supportive relationships, along with the presence of good teamwork, both encouraged and made presenteeism possible. ${ }^{[8]}$ Meta-analytic findings however, have demonstrated a negative association between presenteeism and each of co-worker support, interpersonal relationships, and supervisory support. Despite this, positive support and relationships, can increase presenteeism indirectly via a positive impact upon job satisfaction. ${ }^{[6]}$

Whilst some participants in this study viewed periods of high workload as difficult to cope with and a reason not to attend when ill, others attended work in order to support their colleagues. Previous findings also indicate that high job demands can result in increased absenteeism ${ }^{[33]}$ and presenteeism, ${ }^{[15]}$ with the latter more prevalent in healthcare workers. ${ }^{[34]}$

Participants, primarily charge nurses, reported using their vacation leave to shorten their working day to cope when ill. This is an aspect of both "leaveism"[35] and "adjustment latitude", defined as opportunities to adjust work to one's state of health. ${ }^{[36]}$ The latter has been linked with both increased ${ }^{[26]}$ and decreased presenteeism, suggesting that whilst adjustment latitude facilitates presenteeism, it is also health promoting. ${ }^{[37]}$ Nurses in this study attended work when unwell the day prior to vacation leave to avoid its cancellation, as well as on days when they were paid more. Indirect support for this comes from earlier studies which have demonstrated that absenteeism drops temporarily during periods where workers can earn more, suggesting an increase in presenteeism. ${ }^{[38]}$

\subsection{Personal reasons}

This study has replicated earlier findings on the role of internal attendance standards influencing the likelihood of presen- teeism. ${ }^{[39]}$ Participants also reported the "general" disposition of some people to attend work when unwell. This may indicate that dispositional character traits may play a role in encouraging presenteeism behaviours. As presenteeism was linked with positive occupational attitudes, such as feelings of responsibility and a desire to avoid work piling up, traits such as conscientiousness (one of the Big Five personality characteristics) may play a role. Personality traits, such as the Big Five, have received limited attention in the presenteeism literature $^{[16]}$ and may warrant further study.

Presenteeism was also influenced by the perceived legitimacy of absenteeism. Certain illnesses and those that coincided with important work situations fostered presenteeism as absenteeism was viewed as less legitimate. Minor colds and mental health problems have frequently been reported as "illegitimate" causes of absence, ${ }^{[18]}$ whilst it has also been reported that individuals who are more easily replaced at work view absence as more legitimate. ${ }^{[16]}$

Encouragement from one's family, the need to work and setting a good example for one's children also drove presenteeism in participants in this study. Other studies have also associated having children with increased presenteeism. ${ }^{[15]}$ Some have postulated that individuals with children may use the workplace to escape family responsibility. ${ }^{[40]}$ However the current study provides other responsibility-based reasons why employees with children may exhibit higher presenteeism. Further in-depth exploration of this topic and connections with the literature on work-life balance, may be warranted.

\subsection{Strengths and limitations}

The strengths of the study include that it is the first to consider the perceived reasons for presenteeism in nurses in Malta, using a qualitative methodology that allowed researchers to explore the phenomenon in depth. They were selected in a stratified random manner, minimising bias in their selection whilst also ensuring that both charge nurses and nurses were represented.

Amongst the limitations of the study, the small sample size means that limited inferences can be made about the reported frequency of presenteeism or the nature of emerging explanatory themes. Additionally, as the study involved nurses working with older patients in public medical facilities, the themes encountered may not necessarily apply to nurses working with other patient groups, or to nurses working in private institutions.

\subsection{Practical implications}

Many participants reported that nursing could be detrimental for their own health, describing working while experienc- 
ing chronic (often musculoskeletal) health problems. Such problems, often attributed to manual handling activities and psychosocial factors, are well documented in nursing. ${ }^{[41]}$ The study reaffirms the need to tackle these issues both by means of preventative interventions as well as by policies supportive to nurses with chronic health difficulties.

There are mixed views about the drawbacks and benefits of presenteeism. Whilst presenteeism is often viewed negatively, some have argued that ill workers nonetheless contribute more than if they had failed to attend. ${ }^{[38]}$ The study demonstrated that nurses considered the consequences of their illness and attended when symptoms were considered minor and not contagious, when they judged that they could cope with their work, and noted that sometimes presenteeism could even benefit recovery. However, a lack of clarity about workers' decisions about whether they were too ill to work has also been reported, ${ }^{[19]}$ so their decisions may not always be beneficial to individual health or to the smooth running of organisations. Nurses who felt that absenteeism would be considered illegitimate were likely to attend work when unwell. Such behaviour can give rise to more severe, chronic issues. ${ }^{[42]}$ These findings, together with the fact that individual judgements about attendance can be clouded by considerations concerning remuneration and vacation leave, confirm the need for clear organisational policy development and rigorous implementation.

\section{Conclusions}

The study provides insights into the reasons why nurses working on geriatric wards engage in presenteeism. The findings highlight new avenues for research whilst also suggesting new contributions to theories of presenteeism, for example by inclusion of the Common Sense Model of SelfRegulation. ${ }^{[22,23]}$ Most importantly, the study highlights the need for evidence-based guidance for nurses and their managers, with clear direction as to when presenteeism is acceptable, and when it is not.

\section{CONFLicts OF INTEREST Disclosure}

The authors declare they have no conflicts of interest.

\section{REFERENCES}

[1] Johns G. Presenteeism in the workplace: a review and research agenda. Journal of Organisational Behaviour. 2010; 31(4): 519-542. https://doi.org/10.1002/job.630

[2] Sainsbury Centre for Mental Health. Mental health at work: developing the business case. Policy Paper 8. London, UK: Sainsbury Institute for Mental Health; 2007.

[3] Cooper C, Lu L. Presenteeism as a global phenomenon. Cross Cultural and Strategic Management. 2016; 23(2): 216-231. https: //doi.org/10.1108/CCSM-09-2015-0106

[4] Skagen K, Collins AM. The consequences of sickness presenteeism on health and wellbeing over time: a systematic review. Social Science and Medicine. 2016; 161. https://doi.org/10.1016/j.so cscimed.2016.06.005

[5] Letvak SA, Ruhm CJ, Gupta SN. Nurses' presenteeism and its effects on self-reported quality of care and costs. American Journal of Nursing. 2012; 112(2): 30-38. PMid: 22261652. https: //doi.org/10.1097/01.NAJ.0000411176.15696.f9

[6] Miraglia M, Johns G. Going to work ill: a meta-analysis of the correlates of presenteeism and a dual-path model. Journal of Occupational Health Psychology. 2016; 21(3): 261-283. PMid: 26550958. https://doi.org/10.1037/ocp0000015

[7] Rebmann T, Turner JA, Kunearth AK. Presenteeism attitudes and behaviour among Missouri kindergarten to twelfth grade $(\mathrm{K}-12)$ school nurses. The Journal of School Nurses. 2016; 32(6): 407-415. PMid: 27026665. https://doi.org/10.1177/1059840516637651

[8] Collins A, Cartwright S. Why come into work ill? Individual and organisational factors underlying presenteeism. Employee Relations. 2012; 34(4): 429-442. https ://doi .org/10.1108/0142545121 1236850

[9] Leineweber C, Westerlund H, Hagberg J, et al. Sickness presenteeism among Swedish police officers. Journal of Occupational Rehabilita- tion. 2011; 21(1): 17-22. PMid: 20533079. https ://doi .org/10 $.1007 / \mathrm{s} 10926-010-9249-1$

[10] Gosselin E, Lemyre L, Corneil W. Presenteeism and absenteeism: differentiated understanding of related phenomena. Journal of Occupational Health Psychology. 2013; 18(1): 75-86. PMid: 23276197. https://doi.org/10.1037/a0030932

[11] Thun S, Løvseth LT. A health impairment process of sickness presenteeism in Norwegian physicians: the mediating role of exhaustion. Health. 2016; 8(9): 846-856. https://doi.org/10.4236/heal th. 2016.89089

[12] Ashby K, Mahdon M. Why do employees come to work when ill? An investigation into sickness presence in the workplace. London, UK: The work foundation; 2010 [cited 2016 November 20]. Available from: http://www.mas.org.uk/uploads/artlib/why-d o-employees-come-to-work-when-ill.pdf

[13] Dhaini SR, Zú-iga F, Ausserhofe D. Absenteeism and presenteeism among care workers in Swiss nursing homes and their association with psychosocial work environment: A multi-site cross-sectional study. Gerontology. 2016; 62(4): 386-395. PMid: 26618789. https : //doi.org/10.1159/000442088

[14] Agudelo-Suárez AA, Benavides FG, Felt E, et al. Sickness presenteeism in Spanish-born and immigrant workers in Spain. BMC Public Health. 2010; 10: 791. PMid: 21190564. https ://doi.org/10.1 186/1471-2458-10-791

[15] Arnold D. Determinants of the annual duration of sickness presenteeism: empirical evidence from European data. Labour. 2016; 30(2): 198-212. https://doi.org/10.1111/labr.12053

[16] Johns G. Attendance dynamics at work: the antecedents and correlates of presenteeism, absenteeism and productivity loss. Journal of Occupational Health Psychology. 2011; 16(4): 483-500. PMid: 21875212. https://doi.org/10.1037/a0025153 
[17] Aronsson G, Gustafsson K, Dallner M. Sick but yet at work. An empirical study of sickness presenteeism. Journal of Epidemiology and Community Health. 2000; 54(7): 502-509. PMid: 10846192. https://doi.org/10.1136/jech.54.7.502

[18] Krane 1, Larsen EL, Nielsen CV, et al. Attitudes towards sickness absence and sickness presenteeism in health and care sectors in Norway and Denmark: a qualitative study. BMC Public Health. 2014; 14: 880. PMid: 25160059. https://doi.org/10.1186/1471-2 458-14-880

[19] Szymczak JE, Smathers S, Hoegg C, et al. Reasons why physicians and advanced practice clinicians work while sick. A mixed-method analysis. JAMA Pediatrics. 2015; 169(9): 815-821. PMid: 26146908. https://doi.org/10.1001/jamapediatrics.2015.0684

[20] Eurofound. Sixth European Working Conditions Survey - overview report. Luxembourg: Publications office of the European Union; 2016.

[21] Braun V, Clarke V. Using thematic analysis in psychology. Qualitative Research in Psychology. 2006; 3(2): 77-101. https://doi.or g/10.1191/1478088706qp063oa

[22] Leventhal H, Meyer D, Nerenz D. The common sense representation of illness danger. In Medical psychology, volume II Edited by Rachman S, Oxford, UK: Pergamon Press; 1980.

[23] Moss-Morris R, Weinman J, Petrie KJ, et al. The revised illness perception questionnaire (IPQ-R). Psychology and Health. 2002; 17(1): 1-16. https://doi .org/10.1080/08870440290001494

[24] Diefenbach MA, Leventhal H. The common-sense model of illness representation: theoretic and practical considerations. Journal of Social Distress and the Homeless. 1996; 5(1): 11-38. https: //doi.org/10.1007/BF02090456

[25] Hansson M, Bostrom C, Harms-Ringdahl K. Sickness absence and sickness attendance - what people with neck or back pain think Social Science and Medicine. 2006; 62(9): 2183-2195. PMid: 16280192. https://doi.org/10.1016/j.socscimed.2005.1 0.002

[26] De Vries HJ, Brouwer S, Groothoff JW, et al. Staying at work with chronic nonspecific musculoskeletal pain: a qualitative study of workers' experiences. BMC Musculoskeletal Disorder. 2011; 12: 126. PMid: 21639884. https://doi.org/10.1186/1471-247 4-12-126

[27] Dew K, Keefe V, Small K. 'Choosing' to work when sick: workplace presenteeism. Social Science and Medicine. 2005; 60(10): 22732282. http://dx.doi.org/10.1186/1478-4505-9-20

[28] Mlakar P, Stare J. Some characteristics of employees as risk factors for presenteeism. International Public Administration Review. 2013; XI(2): 31-55. https://doi.org/10.17573/ipar.2013.2.a02

[29] Çetin M. An exploratory study of presenteeism in Turkish context. Emerging Markets Journal. 2016; 6(1): 25-38. https ://doi .org/ 10.5195/EMAJ . 2016.93

[30] Schaufeli WB, Salanova M, Gonzalez-Romá V, et al. The measurement of engagement and burnout: A confirmative analytic ap- proach. Journal of Happiness Studies. 2002; 3(1): 71-92. https : //doi.org/10.1023/A:1015630930326

[31] Tan PC, Robinson G, Jayathissa S, et al. Coming to work sick: a survey of hospital doctors in New Zealand. The New Zealand Medical Journal. 2014; 127(1399): 23-35. PMid: 25145303.

[32] Rantanen I, Tuominen R. Relative magnitude of presenteeism and absenteeism and work-related factors affecting them among health care professionals. International Archives of Occupational and Environmental Health. 2011; 84(2): 225-230. PMid: 21140162. https : //doi.org/10.1007/s00420-010-0604-5

[33] Hultin H, Hallqvist J, Alexanderson K, et al. Work-related psychosocial events as triggers of sick leave - results from a Swedish case-crossover study. BMC Public Health. 2011; 11: 175. PMid: 21429193. https://doi .org/10.1186/1471-2458-11-175

[34] Elstad JI, Vabø M. Job stress, sickness absence and sickness presenteeism in Nordic elderly care. Scandinavian Journal of Public Health. 2008; 36(5): 467-474. PMid: 18635730. https://doi .org/10.1 $177 / 1403494808089557$

[35] Hesketh I, Cooper CL. Leaveism at work. Occupational Medicine. 2014; 64(3): 146-147. PMid: 24706465. https ://doi .org/10.1 093/occmed/kqu025

[36] Johansson G, Lundberg O, Lundberg I. Return to work and adjustment latitude among employees on long-term sickness absence. Journal of Occupational Rehabilitation. 2006; 16(2):185-195. PMid: 16710761. https ://doi .org/10.1007/s10926-006-9020-9

[37] Gerich J. Sickness presence, sick leave and adjustment latitude. International Journal of Occupational Medicine and Environmental Health. 2014; 27(5): 736-746. PMid: 25257339. https ://doi .or $\mathrm{g} / 10.2478 / \mathrm{s} 13382-014-0311-7$

[38] Baker-McClearn D, Greasley K, Dale J, et al. Absence management and presenteeism: the pressures on employees to attend work and the impact of attendance on performance. Human Resource Management Journal. 2010; 20(3): 311-328. https ://doi .org/10.1111/j . 17 48-8583.2009.00118. $\mathrm{x}$

[39] Robertson I, Leach D, Doerner N, et al. Poor health but not absent. Prevalence, predictors and outcomes of presenteeism. Journal of Occupational and Environmental Medicine. 2012; 54(11): 13441349. PMid: 23041976. https://doi.org/10.1097/JOM. Ob01 3e31825dff $4 \mathrm{~b}$

[40] Hochschild A. The time bind. Journal of Labor and Society. 1997; 1(2): 21-29. https://doi.org/10.1111/j.1743-4580.1997 .tb00019.x

[41] Bos E, Krol B, van der Star L, et al. Risk factors and musculoskeletal complains in non-specialized nurses, IC nurses, operation room nurses, and X-ray technologists. International Archives of Occupational and Environmental Health. 2007; 80(3): 198-206. PMid: 16799823. https://doi.org/10.1007/s00420-006-0121-8

[42] Taloyan M, Aronsson G, Leinewber C, et al. Sickness presenteeism predicts suboptimal self-rated health and sickness absence: a nationally representative study of the Swedish working population. PLOS One. 2012; 7(9): e44721. PMid: 22984547. https: //doi.org/10.1371/journal.pone.0044721 